\title{
Technical note: Assessing the functional capacity of mitochondria isolated from lactating mammary tissue: Choose your chelating agent wisely
}

\author{
D. L. Hadsell, ${ }^{*} \dagger^{1}$ J. George, ${ }^{*}$ P. A. Abraham, $\ddagger$ R. J. Collier,ł and B. D. Lambert§\# \\ *USDA/ARS Children's Nutrition Research Center, Department of Pediatrics, and \\ †Department of Molecular and Cellular Biology, Baylor College of Medicine, Houston, TX 77030 \\ ‡Department of Animal Science, University of Arizona, Tucson 11111 \\ $\S$ Department of Animal Science, Tarleton State University, Stephenville, TX 76402 \\ \#Agrilife Research, Stephenville, TX 76401
}

\begin{abstract}
Previous work has indicated that respiratory activity of mitochondrial preparations prepared from lactating mammary tissue is often much lower than that of mitochondria isolated from other organs such as the liver. Initial studies in our own laboratory also found that mammary mitochondria prepared from lactating mice had much lower ATP synthesis activity than those isolated from liver tissue obtained from the same animals. In this paper, we describe an improved procedure for obtaining coupled mitochondria from the mammary tissue of lactating mice. Using a high-throughput assay for mitochondrial ATP synthesis, we demonstrated that mammary mitochondria, unlike liver mitochondria, are sensitive to the concentration of bovine serum albumin and to the choice of chelating agent used in the preparation and assay buffers. Mammary mitochondria prepared and assayed in buffers containing $1 \mathrm{~m} M$ ethylene glycol-bis-( $\beta$-aminoethyl ether)-N, $\mathrm{N}^{\prime}$ tetraacetic acid (EGTA) and $0.4 \%$ bovine serum albumin have a similar ATP synthesis activity as liver mitochondria. In addition, we show that the chelating agent EDTA ablates the ATP synthesis capacity of mammary mitochondria through a mechanism that does not involve the release of cytochrome c. We also demonstrate that these improved isolation and assay procedures are both scalable and applicable to bovine mammary tissue, and we describe optimal conditions for cryopreservation and recovery of functionally active mitochondria. This work will facilitate future studies aimed at determining the importance of mammary mitochondria to milk production.
\end{abstract}

Key words: lactation, adenosine triphosphate, mitochondria, mammary

Received May 13, 2008.

Accepted December 2, 2008.

${ }^{1}$ Corresponding author: dhadsell@bcm.tmc.edu
Prior experiments isolating and analyzing mitochondria from the mammary tissue of lactating mice have been based on procedures that had previously been developed using liver mitochondria and then applied to mammary mitochondria from both the cow and the mouse (Mehard, 1974; Dreels and Baumrucker, 1982; Darley-Usmar et al., 1987; Lindberg et al., 1989; Pallotti and Lenaz, 2001). Based on these studies, mammary mitochondria exhibited a lower degree of respiratory coupling than did liver mitochondria. Although the reason for this has never been fully defined, previous workers suggested that NEFA or milk-associated calcium could cause uncoupling (Nelson et al., 1962; Mehard, 1974; Dreels and Baumrucker, 1982). That NEFA have the ability to uncouple oxidative phosphorylation in isolated mitochondria has been known for almost 50 yr and was initially demonstrated with mitochondrial preparations isolated from the wing muscles of insects (Liu and Chin, 1964; Wojtczak et al., 1968). Since then, a large number of studies have been conducted in various systems that have led to the idea that specific NEFA work through a small number of potential mechanisms to uncouple mitochondrial ATP synthesis from electron transport (Kadenbach, 2003). With mammary tissue, early studies found that inclusion of BSA in both the isolation and assay buffers at concentrations from 0.1 to $1 \%$ (wt/vol) improved mitochondrial respiratory control ratios (Nelson et al., 1962; Mehard, 1974). In addition, studies with lactating guinea pigs found that mammary gland mitochondria were more sensitive to the uncoupling effects of NEFA than were liver mitochondria (Nelson et al., 1962).

Mitochondria have long been known to accumulate calcium as a part of their normal function (Nicholls, 2005). However, when calcium concentrations exceed a certain threshold, uncoupling occurs (Gunter et al., 2004; Nicholls, 2005). This calcium-dependent uncoupling was first described almost $50 \mathrm{yr}$ ago (Saris and Carafoli, 2005) and is now known to occur through activation of the mitochondrial permeability transition 
pore (Gunter et al., 2004; Nicholls, 2005; Saris and Carafoli, 2005).

To overcome calcium-dependent uncoupling, the chelating agents EDTA or ethylene glycol-bis-( $\beta$ aminoethyl ether)-N, $\mathrm{N}^{\prime}$ tetraacetic acid (EGTA) are commonly used in both the preparation and analysis of mitochondria from various tissues (Pallotti and Lenaz, 2001). In this regard, it is well established that EDTA removes both calcium and magnesium from mitochondria during preparation (Cassidy et al., 1969; Lehninger et al., 1969). Both compounds have often been used interchangeably because of similarities in their affinities for calcium (Schmid and Reilley, 1957). However, EDTA, because of its high affinity for magnesium, can negatively affect the coupling of mitochondria isolated from certain tissues (Lund and Wiggins, 1990; Rodriguez-Zavala and Moreno-Sanchez, 1998; Cadenas and Brand, 2000). With intestinal mitochondria, the use of EDTA causes a loss of coupling that was demonstrated to occur through the release of cytochrome c during the isolation procedure (Masola and Evered, 1984). The effect of EDTA on mammary mitochondrial preparations has not been systematically evaluated.

The primary goal of the work described in this paper was to test the hypothesis that choice of chelating agent would affect the ATP synthesis capacity of mitochondria isolated from the mammary tissue of lactating mice through effecting cytochrome c release. Secondary goals of the work were to assess the scalability of the assay, optimize the conditions for cryopreservation of mitochondrial preparations, and conduct initial studies on the applicability of the methods to mammary tissue from lactating cows. The results present the evolution and refinement of a technique that is now practical, functional, and applicable to mammary tissue mitochondria from lactating mice as well as from dairy cows.

Mitochondrial function was compared between liver and mammary tissue harvested from lactating CD-1 (d 8 postpartum) mice using a 96-well format luciferasecoupled ATP assay (Manfredi et al., 2002). In our initial comparisons, 250-mg samples of fresh tissue were first minced briefly in $2 \mathrm{~mL}$ of ice-cold homogenization buffer containing $5 \mathrm{~m} M$ 3-morpholinopropanesulfonic acid (MOPS; Fisher Scientific, Pittsburgh, PA), $0.3 M$

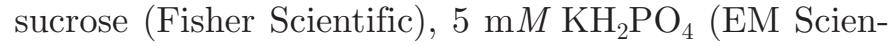
tific, Carson City, NV) $1 \mathrm{~m} M$ EGTA (Sigma Chemical Company, St. Louis, MO), and $0.1 \%$ (wt/vol) BSA (Fraction V, Fisher Scientific) that was adjusted to $\mathrm{pH}$ 7.4 with $1 N \mathrm{KOH}$ (Sigma Chemical Co.).

Tissues were homogenized on ice with 10 strokes in a Wheaton 5-mL Potter Elvejhem homogenizer (Fisher Scientific) driven by a Boden drill motor (Talbots Engineering Corp., Emerson, NJ) at 2,250 rpm. The homogenate was centrifuged at 1,000 $\times g$ for $10 \mathrm{~min}$ at $4^{\circ} \mathrm{C}$, and the resulting supernatant was centrifuged at $10,000 \times g$ for $10 \mathrm{~min}$ at $4^{\circ} \mathrm{C}$. The resulting crude mitochondrial pellet was resuspended in $0.2 \mathrm{~mL}$ of homogenization buffer and then layered on top of a discontinuous density gradient.

Density gradients for further purification of crude mitochondria consisted of $6 \mathrm{~mL}$ of $30 \%$ and $6 \mathrm{~mL}$ of $70 \%$ Percoll (Amersham Biosciences, Uppsala, Sweden) containing $70 \%$ and $30 \%$ (vol/vol) of $0.25 \mathrm{M}$ sucrose, respectively. The gradients were centrifuged at 53,000 $\times g$ for 40 min in a Beckman SW28 (Beckman Coulter Inc., Fullerton, CA) swinging bucket rotor (Mootha et al., 2003). The mitochondria collected from the 30 to $70 \%$ interface were washed in homogenization buffer 3 times. After each wash, the mitochondria were pelleted by centrifugation for $10 \mathrm{~min}$ at $10,000 \times g$ at $4^{\circ} \mathrm{C}$ and then resuspended in $0.2 \mathrm{~mL}$ of homogenization buffer. After the third wash, the pellet was resuspended in 0.2 $\mathrm{mL}$ of ATP synthesis assay buffer (described below), the volume was recorded, and one-fifth of the sample was pelleted and then resuspended in PBS $(136 \mathrm{mM} \mathrm{NaCl}$, $2.6 \mathrm{~m} M \mathrm{KCl}, 10 \mathrm{~m} M \mathrm{Na}_{2} \mathrm{HPO}_{4}, 1.76 \mathrm{~m} M \mathrm{KH}_{2} \mathrm{PO}_{4}$ ) for determining protein concentration. Protein concentration was determined using the bicinchoninic acid assay (Pierce Chemical Corp., Rockford, IL). The resulting protein concentrations were then used to calculate yield of mitochondria and to standardize the amount of mitochondria within the ATP synthesis assay.

To measure ATP synthesis, Percoll-purified mitochondria were resuspended in ice-cold assay buffer $(\mathrm{pH}$ 7.4) containing $150 \mathrm{mM} \mathrm{KCl}$ (Fisher Scientific), 25 $\mathrm{m} M$ Tris-HCl (Fisher Scientific), $2 \mathrm{~m} M$ EDTA (Sigma

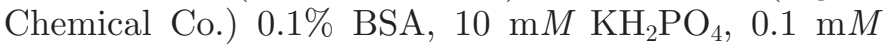
$\mathrm{MgCl}_{2}$ (Fisher Scientific), $1 \mathrm{mM}$ malate (Sigma Chemical Co.), and $1 \mathrm{~m} M$ pyruvate (Sigma Chemical Co.). To each sample well of a 96 -well white microtiter plate (Thermo Scientific, Waltham, MA), $100 \mu \mathrm{g}$ of mitochondrial protein was added in a volume of $0.2 \mathrm{~mL}$. The luciferase reaction was carried out in a multiwellformatted luminometer (Luminoscan, Ascent, Thermo Scientific, Waltham, MA). The instrument initiated each reaction by adding $0.1 \mathrm{~mL}$ of luciferin-luciferase reaction buffer containing $0.8 \mathrm{~m} M$ luciferin (Molecular Probes, Invitrogen, Carlsbad, CA), $20 \mu \mathrm{g} / \mathrm{mL} \mathrm{lu-}$ ciferase (Roche Diagnostics, Basel, Switzerland.), 0.1 $\mathrm{m} M$ adenosine diphosphate (Sigma Chemical Co.) in $0.5 M$ Tris acetate (Fisher Scientific) buffer at $\mathrm{pH}$ 7.5. An integrated luminescence was then recorded at 15-s intervals for $1 \mathrm{~min}$ at room temperature.

Luminescence measurements were used to calculate an initial rate constant for each well. Parallel wells containing ATP standards (Sigma Chemical Co.) were added in $0.1 \mathrm{~mL}$ of assay buffer at concentrations of 0.8 to 25 

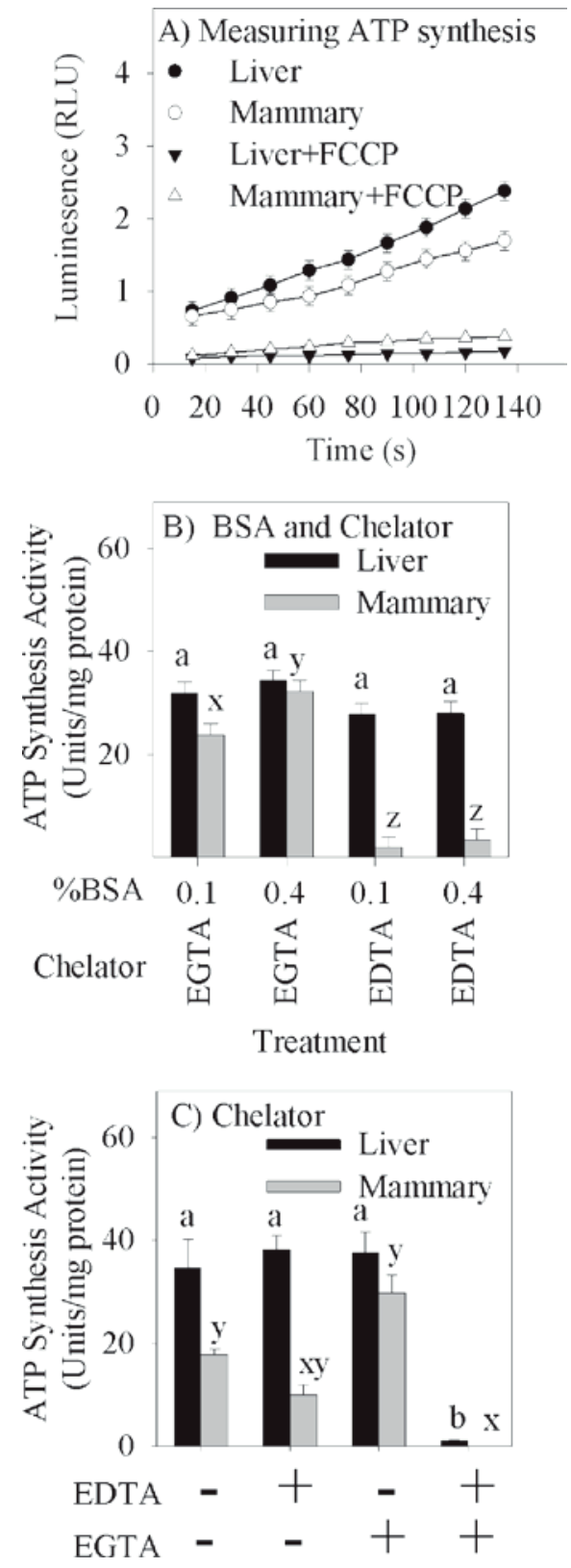

Figure 1. The optimal conditions for isolation and analysis of functional mitochondria from the mammary tissue of lactating mice. Activity of ATP synthesis was measured using a luciferase-coupled assay. Luminescence (RLU, relative light units) was measured over time in mitochondrial samples $(100 \mu \mathrm{g})$ that were incubated with ADP, malate, and pyruvate in the presence of luciferin and firefly luciferase (panel A). The requirement for a mitochondrial proton gradient in the assay was demonstrated by incubating the preparations with the uncoupling agent [carbonyl cyanide 4-(trifluoromethoxy) phenyl hydrazone, FCCP]. Optimal ATP synthesis activity was achieved in both liver and mammary gland mitochondria by using ethylene glycol-bis( $\beta$-aminoethyl ether)- $\mathrm{N}, \mathrm{N}^{\prime}$ tetraacetic acid (EGTA) as a chelating agent in both the homogenization and assay buffers and by including BSA at a concentration of $0.4 \%$ (panel B). The effect of chelating agent was tested again by evaluating ATP synthesis in the absence or presence of EDTA or EGTA (panel C). A unit of ATP synthesis activity is defined as 1 micromole of ATP produced per minute. Each bar represents the mean \pm SEM from 3 different animals. Bars of similar color with different letters differ $(P<0.05)$. $\mu M$ to produce a calibration curve. The luminescence for each standard was measured once at $15 \mathrm{~s}$ following the addition of reaction buffer. Running the samples and calibration curve on the same plate allowed for mitochondrial ATP synthesis activity to be measured and expressed in terms of units per milligram of mitochondrial protein, where 1 unit equals 1 micromole of ATP produced per minute. To validate that the assay was measuring mitochondrial ATP synthesis, assays were conducted with liver or mammary mitochondria in the presence or absence of the protonophore carbonyl cyanide 4-(trifluoromethoxy) phenyl hydrazone (FCCP, Sigma Chemical Co.; Benz and McLaughlin, 1983). The presence of $0.25 \mathrm{~m} M \mathrm{FCCP}$ in the assay inhibited the time-dependent increase in luminescence (Figure 1A). This result demonstrates that a mitochondrial proton gradient was required for production of the ATP that was detected in the assay.

The results of our first comparisons of ATP synthesis activity in mitochondria prepared from liver and mammary tissue demonstrated that liver mitochondria had easily detectable ATP synthesis activity, whereas that of mammary mitochondria was low. This result is illustrated in Figure 1B by the low ATP synthesis activity observed in mammary mitochondria in the presence of EDTA with $0.1 \%$ BSA. At this point, there were 2 variables in both the isolation and assay protocols that were under consideration. The first was the concentration of BSA and the second was the choice of chelating agent.

To determine the relative importance of BSA concentrations and the choice of chelating agent in the analysis of mammary mitochondrial function, 3 studies were done. All 3 studies consisted of independent liver or mammary mitochondrial samples prepared from 3 lactating CD-1 mice for each treatment group. Treatments were administered either by subdividing the mammary tissue from each mouse equally among the various treatment groups or by splitting the homogenate on a volume basis. All samples were assayed in duplicate. The average intra- and interassay coefficients of variation for the ATP synthesis assay was 6.1 and $11.3 \%$, respectively. The first study tested the effect of BSA, the second study compared EDTA and EGTA in either 0.1 or $0.4 \%$ BSA, and the third study determined the effect of these 2 chelating agents in the presence of $0.4 \%$ BSA on both ATP synthesis and mitochondrial cytochrome $\mathrm{c}$ and cytochrome c oxidase content.

In the first study, the effect of 0.1 or $0.4 \%$ BSA in both the homogenization buffer and assay buffer on mitochondrial yield and ATP synthesis capacity was compared among liver and mammary tissue. For this study, EGTA was the chelating agent in both the homogenization and assay buffers. The yield (mean 
\pm SEM) of mitochondrial protein from liver $(0.36 \pm$ 0.02 and $0.36 \pm 0.06 \mathrm{mg} / \mathrm{g}$ of tissue for 0.1 or $0.4 \%$ BSA, respectively) and mammary gland $(0.30 \pm 0.01$ and $0.28 \pm 0.01 \mathrm{mg} / \mathrm{g}$ of tissue for 0.1 or $0.4 \% \mathrm{BSA}$, respectively) were not affected by the concentration of BSA in the homogenization buffer. Liver mitochondrial ATP synthesis activity was not affected by BSA concentration $(17.93 \pm 3.09$ and $18.13 \pm 2.24 \mu \mathrm{mol} / \mathrm{min}$ per mg of protein for 0.1 and $0.4 \%$ BSA, respectively). In contrast, mammary mitochondrial ATP synthesis activity was increased $(P<0.05) 3$-fold by increasing the BSA concentration $(7.42 \pm 0.57$ and $21.37 \pm 1.06$ $\mu \mathrm{mol} / \mathrm{min}$ per $\mathrm{mg}$ of protein for 0.1 and $0.4 \% \mathrm{BSA}$, respectively).

In the second study, both BSA and chelating agent were evaluated simultaneously. The yield of mitochondrial protein in this study was similar among samples prepared in 0.1 and $0.4 \% \mathrm{BSA}$ and averaged $0.36 \pm$ 0.04 and $0.40 \pm 0.03 \mathrm{mg} / \mathrm{g}$ of tissue for mammary gland and liver, respectively. Although liver mitochondria were little affected by either choice of chelating agent or concentration of BSA (Figure 1B), ATP synthesis activity of mammary mitochondria was increased with $0.4 \%$ BSA $(P<0.05)$ and improved $(P<0.0001)$ with EGTA in the assay buffer. Mammary mitochondria had very little activity in the presence of EDTA. The BSA effect agrees with a previous comparison of liver and mammary mitochondria prepared from lactating guinea pigs (Nelson et al., 1962). Thus, the mitochondria from liver and mammary gland either have a differential sensitivity to NEFA or the concentrations of NEFA are higher in mitochondria prepared from mammary gland than in those prepared from liver. Studies in lactating mice and guinea pigs suggest that mammary tissue NEFA concentrations could range from 2 to $10 \mu \mathrm{mol} / \mathrm{g}$ of wet weight (Kuhn, 1967; Anzai et al., 1979). In addition, analysis of lipid synthesis in the lactating mouse has demonstrated that tissue lipid concentrations may be up to 4-fold higher in the mammary gland compared with the liver (Smith et al., 1969). These results suggest that NEFA are considerably higher in mammary tissue than in liver and probably contribute to the differences observed in the present studies. The Fraction V BSA used in this study probably contained from 0.2 to 0.5 moles of fatty acid per mole of protein (Chen, 1967). Albumin is known to have a high affinity binding capacity for 5 to 7 moles of fatty acid per mole of protein (Davis and Dubos, 1948; Goodman, 1958). Thus, the fact that increasing the BSA content 4-fold allowed mammary mitochondria to display similar activity to that of liver suggests that the mammary mitochondrial preparations use in this study had at least 4-fold more fatty acid than that present in liver. This conclusion would be consistent with other examples of NEFA-dependent uncoupling in other physiological or pathophysiological settings (Boime et al., 1970; Brustovetsky et al., 1992; Roussel et al., 2003).

Previously published studies suggested that the elevated tissue calcium in the mammary gland caused uncoupling compared with liver tissue (Dreels and Baumrucker, 1982). Our own initial studies demonstrated that mammary mitochondria had limited ATP synthesis activity in the presence of EDTA, but were fully functional in the presence of EGTA. To follow up on these observations, a third and final study was conducted comparing the effect of these chelating agents evaluated in all possible combinations, including the complete absence and presence of both (Figure 1C). For this study, all mitochondria were prepared with $0.4 \%$ BSA in homogenization buffer containing EGTA. The various chelator treatments were then administered at the point where each Percoll-purified preparation was pelleted and then resuspended in assay buffer. Sample replication in this experiment is similar to the previous experiments in that individual preparations were made from each of 3 mice and subdivided into the various treatment regimens during preparation. Yield of mitochondrial protein for this experiment was $0.29 \pm 0.05$ and $0.20 \pm 0.01 \mathrm{mg} / \mathrm{g}$ of tissue for liver and mammary gland, respectively. Liver mitochondrial ATP synthesis activity in assay buffer containing no chelating agents was similar to that observed with EDTA and EGTA, but dramatically reduced $(P<0.05)$ in the presence of both chelators. In contrast, mammary mitochondrial ATP synthesis capacity was inhibited $(P<0.05)$ by removing EGTA or by switching from EGTA to EDTA. The presence of both EDTA and EGTA completely abolished ATP synthesis activity in mammary mitochondria. Activity of ATP synthesis was similar among liver and mammary mitochondria as long as they were assayed in the presence of EGTA only. These data suggest that liver and mammary mitochondrial have differential sensitivity to chelation of calcium and magnesium.

Previous work has demonstrated that intestinal mitochondria isolated and assayed in the presence of EDTA were nonfunctional and had undergone permeability transition, as indicated by lower cytochrome c levels (Masola and Evered, 1984). To determine if differences in ATP synthesis capacity in mammary mitochondria in response to EDTA or EGTA could be linked to a similar type of mitochondrial permeability transition, the abundance of cytochrome c and cytochrome c oxidase was measured in the mitochondrial preparations described for experiment 3 above (Figure 2). Western blotting was done using sheep polyclonal cytochrome c antibody from Abcam (Abcam Inc., Cambridge MA) at a 1:5,000 dilution. The secondary antibody was anti- 


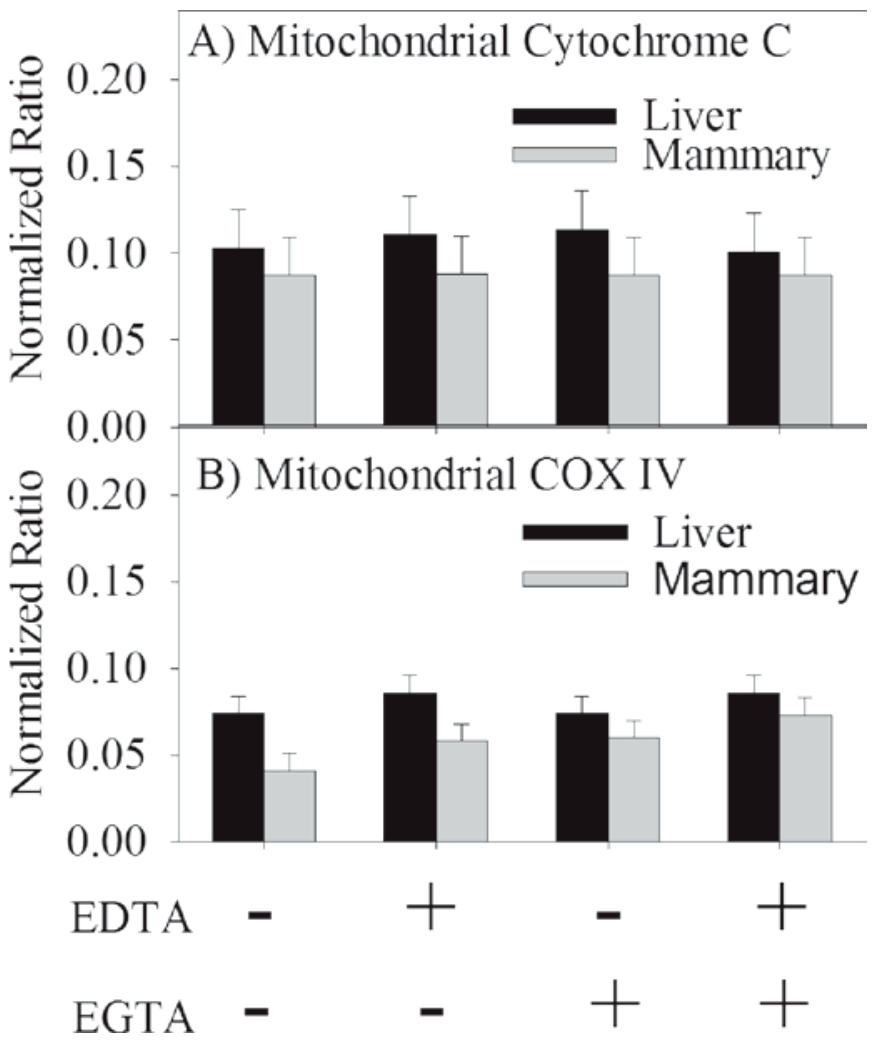

Figure 2. Mitochondrial cytochrome c and cytochrome c oxidase (COX IV) abundance were little affected by different chelating agents. Western blotting followed by densitometry was used to determine the effect of EDTA or ethylene glycol-bis-( $\beta$-aminoethyl ether)-N, $\mathrm{N}^{\prime}$ tetraacetic acid (EGTA) on mitochondrial content of cytochrome c (panel A) or cytochrome c oxidase (panel B). Each bar represents the mean \pm SEM for 3 animals. A significant main effect of tissue was detected $(P$ $<0.01)$. No differences were detected with regard to chelating agent.

sheep horseradish peroxidase (1:1,000 dilution, Jackson Immuno Research Labs, West Grove, PA). To control for gel loading, Western blotting for cytochrome c oxidase (COX) IV was conducted using a mouse monoclonal antibody (Abcam Inc.) at a dilution of 1:2,500. The secondary antibody for this Western blot was antimouse horseradish peroxidase (1:1,000 dilution, Amersham Biosciences, Piscataway, NJ). Forty micrograms of protein was loaded per lane onto a $15 \%$ acrylamide running gel (4\% stacking gel). Electrophoresis was done at $30 \mathrm{~mA}$ for $1 \mathrm{~h}$. This gel was transferred onto a Protran nitrocellulose membrane (Schleicher and Scheul, Dassel, Germany) overnight at $44 \mathrm{~mA}$ and $4^{\circ} \mathrm{C}$. Densitometry was conducted using Image Pro analysis program (Media Cybernetics, Bethesda, MD). For both liver and mammary mitochondria, cytochrome c was similar among all combinations of chelating agent (Figure 2A). Western blotting for cytochrome c oxidase provided a control for loading differences (Figure 2B). The abundance of this protein was modestly lower in mammary mitochondria compared with liver, but similar among all chelator treatments. This result suggests that loss of ATP synthesis capacity in mammary mitochondria is not linked with release of cytochrome $\mathrm{c}$ when exposed to EDTA.

Studies conducted over 40 yr ago demonstrated that EDTA removes some $\mathrm{Ca}^{2+}$ and $\mathrm{Mg}^{2+}$ from mitochondria during preparation (Cassidy et al., 1969; Lehninger et al., 1969). Concentrations of $\mathrm{Ca}^{2+}$ are about 10-fold higher in the mammary gland than in liver, and previous work has suggested that these increased concentrations could interfere with the isolation of coupled mitochondria (Rubin, 1974; Baumrucker, 1978; Dreels and Baumrucker, 1982). However, the present studies point to a potential effect related to $\mathrm{Mg}^{2+}$ rather than $\mathrm{Ca}^{2+}$. Recent work with yeast mitochondria has demonstrated that EDTA is much more effective at depleting mitochondrial $\mathrm{Mg}^{2+}$ than EGTA (Bradshaw and Pfeiffer, 2006). This observation, coupled with the results of the present study, suggests that mammary mitochondria are selectively sensitive to the depletion of $\mathrm{Mg}^{2+}$. Although the reason for this difference is unclear, there have been several $\mathrm{Mg}^{2+}$ transporters described that could play a role (Schmitz et al., 2007). Most interestingly, a mitochondrial $\mathrm{Mg}^{2+}$ transporter, mrs2p, has recently been described in yeast and humans (Zsurka et al., 2001; Schindl et al., 2007). Perhaps differential expression of this or other transport proteins could explain the differential effects of EDTA observed in the present study.

Having established a set of optimal conditions for the isolation and analysis of mammary mitochondria from fresh lactating tissue, we next chose to develop conditions for cryopreservation and storage that would facilitate the practical application of these techniques to quantitative studies on the relationships between mitochondrial function and milk production in lactating animals. The variables tested in this experiment were based on previous studies examining the effect of cryostorage on the function of mitochondria from muscle tissue (Kuznetsov et al., 2003). The 3 variables tested were dimethyl sulfoxide (DMSO) concentration (20 vs. $30 \%, \mathrm{vol} / \mathrm{vol}$ ), volume of freezing buffer (0.1 vs. $0.2 \mathrm{~mL}$ ), and type of thawing procedure (immediate dilution vs. delayed replacement of the freezing buffer with assay buffer). Lactating CD-1 mice ( $\mathrm{n}=$ 3) were sacrificed and both \#4 mammary glands from each mouse were harvested. Liver tissue from a single mouse was also included in the experiment as a quality control sample for comparison with the previous 2 studies. Mitochondria were prepared using the optimized homogenization buffer that contained $0.4 \%$ BSA and $1 \mathrm{~m} M$ EGTA. After resuspending the final pellet in $0.2 \mathrm{~mL}$ of homogenization buffer, each mitochondrial suspension was split into 8 equal parts and again pel- 


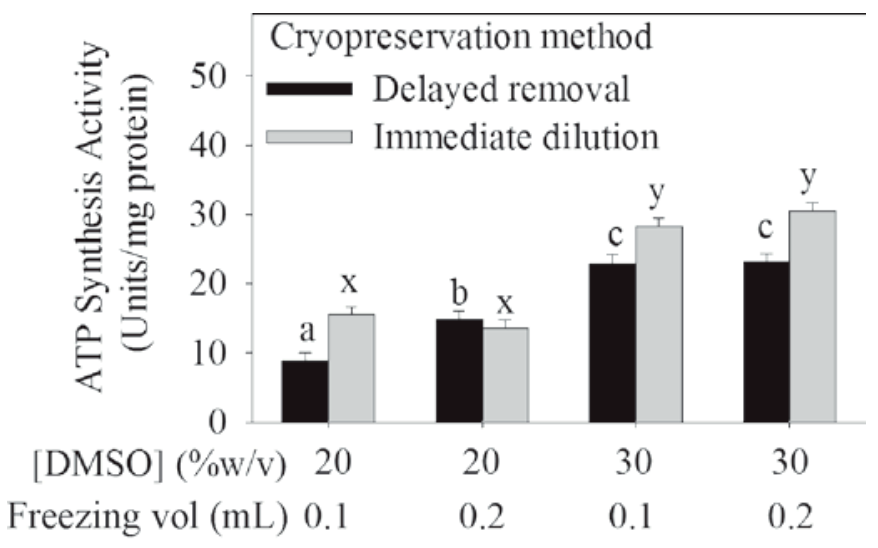

Treatment (DMSO/media volume)

Figure 3. Optimization of mitochondrial cryopreservation and recovery. Maximal ATP synthesis activity was achieved in cryopreserved mitochondria by freezing the samples $(3.31 \pm 0.37 \mathrm{mg}$ mitochondrial protein) in $0.2 \mathrm{~mL}$ of a buffer containing $30 \%$ dimethyl sulfoxide and by rapidly diluting the dimethyl sulfoxide during thawing. Each symbol represents the mean \pm SEM for 3 independent animals. A unit of ATP synthesis activity is defined as 1 micromole of ATP produced per minute. Similarly shaded bars with different letters differ $(P<0.05)$. Liver and mammary mitochondria had similar ATP synthesis capacity in EGTA with $0.4 \%$ BSA.

leted at $10,000 \times g$. Of these, 2 pellets each were frozen in either 0.1 or $0.2 \mathrm{~mL}$ of cryostorage buffer $\mathrm{A}(0.21 \mathrm{M}$ mannitol, $0.07 M$ sucrose, $30 \%$ DMSO, 0.4\% BSA, pH 7.4). In a similar fashion, 2 pellets each were frozen in 0.1 or $0.2 \mathrm{~mL}$ of cryostorage buffer B (0.21 $\mathrm{M}$ mannitol, $0.07 M$ sucrose, $20 \%$ DMSO, $0.4 \%$ BSA, $\mathrm{pH} 7.4$ ) and 2 pellets were frozen in $0.2 \mathrm{~mL}$ of cryostorage buffer B. All mitochondrial pellets were flash frozen and then stored in liquid nitrogen for $48 \mathrm{~h}$.

To recover the cryopreserved mitochondria, 2 types of thawing procedures were employed. The first was immediate dilution of the cryostorage buffer in $0.9 \mathrm{~mL}$ of assay buffer at $37^{\circ} \mathrm{C}$, followed by incubated at $37^{\circ} \mathrm{C}$ for $2 \mathrm{~min}$, and then centrifugation at $10,000 \times g$ for 2 min. The second was the delayed removal of cryostorage buffer, where $0.2 \mathrm{~mL}$ of assay buffer at $37^{\circ} \mathrm{C}$ was added to frozen mitochondria that were then incubated at $37^{\circ} \mathrm{C}$ for $5 \mathrm{~min}$ and then centrifuged $10,000 \times g$ for 10 min at $4^{\circ} \mathrm{C}$. The pellets for both recovery procedures were then resuspended in $0.2 \mathrm{~mL}$ of assay buffer and ATP synthesis was assayed.

Of the 3 cryopreservation variables tested, DMSO concentration $(P<0.0001)$ and thawing procedure $(P<0.0001)$ had the most significant effect on ATP synthesis activity (Figure 3). Interestingly, there was also a significant 3 -way interaction $(P<0.01)$ in that freezing volume affected ATP synthesis activity only in mitochondria that were cryopreserved with $20 \%$ DMSO and recovered by the delayed recovery procedure. Importantly, optimal ATP synthesis capacity was obtained in mammary mitochondria that were frozen in $0.2 \mathrm{~mL}$ of cryostorage buffer containing 30\% DMSO and recovered by the immediate dilution into assay buffer at $37^{\circ} \mathrm{C}$. The ATP synthesis capacity of these optimally stored mammary mitochondria was maintained at $91 \pm$ $3 \%$ of that of fresh mitochondria (Figure 1 vs. Figure $3)$. This result supports the conclusion that cryopreservation of mammary mitochondria following the optimal procedure outlined above will produce samples that accurately reflect the mitochondrial activity present in fresh mammary biopsy material.

All of the experiments described above used $250 \mathrm{mg}$ of tissue for the preparation of mitochondria and 100 $\mu \mathrm{g}$ of mitochondrial protein assayed in duplicate for the ATP synthesis assay. Under these conditions, the yield of mitochondrial protein from the liver was quite repeatable displaying an inter-experiment coefficient of variation of $20 \%$. Mammary mitochondria, on the other hand, were more variable in their preparation with the yield across the 3 experiments varying by $94 \%$. Because the availability of biopsy material could be a limiting factor in these procedures, an experiment was done to determined the effect of using different starting amounts of tissue $(250,100,50$, and $25 \mathrm{mg})$ on both mitochondrial recovery and on ATP synthesis activity. For this experiment, decreasing amounts of mammary tissue from 3 lactating mice were used to isolate mitochondria. The yield of mitochondrial protein per unit of starting tissue was significantly reduced $(P<0.05)$ when the amount of starting tissue was $<50 \mathrm{mg}(0.20 \pm 0.01$, $0.20 \pm 0.01,0.17 \pm 0.04$, and $0.02 \pm 0.02 \mathrm{mg} / \mathrm{g}$ of tissue for $250,100,50$, and $25 \mathrm{mg}$, respectively). Although the effect of starting tissue amount on ATP synthesis activity was not significant $(43.5 \pm 7.9,57.8 \pm 7.9,29.0 \pm$ 7.9 , and $33.0 \pm 7.9$ units $/ \mathrm{mg}$ of protein for $250,100,50$, and $25 \mathrm{mg}$ of tissue, respectively), examination of the means suggests that $100 \mathrm{mg}$ might be a minimal sample size. In addition, the yield of mitochondrial would be expected to vary by as much as 2-fold across different experiments. A potential explanation for this could be heterogeneity of the starting tissue.

The same isolation, cryopreservation, and assay procedures were applied to samples of liver and mammary tissue isolated from lactating dairy cows. For these studies, 3 lactating Holstein cows were biopsied 2 to 4 $\mathrm{h}$ after the morning milking to provide liver and mammary tissue samples. These animals were maintained on a pasture-based management system, were $300 \pm$ $60 \mathrm{~d}$ in milk, and were producing $20 \pm 2 \mathrm{~kg} / \mathrm{d}$. The amount of starting tissue used was $139.3 \pm 15.7 \mathrm{mg}$ for liver and $134.3 \pm 5.8 \mathrm{mg}$ for mammary gland. The yield of mitochondria was $0.07 \pm 0.03$ and $0.17 \pm 0.03$ $\mathrm{mg} / \mathrm{g}$ of tissue for mammary gland and liver, respectively. When using $50 \mu \mathrm{g}$ of mitochondrial protein in 
each well of the assay plate, ATP synthesis activity was observed to be $4.13 \pm 3.40$ and $6.38 \pm 2.37$ units $/ \mathrm{mg}$ of protein for mammary gland and liver, respectively. Thus, in these bovine samples, as previously observed in the mouse samples, this mitochondrial preparation and analysis procedure produces samples from liver and mammary gland with similar ATP synthesis activity. The fact that ATP synthesis activity was lower in the cow than in the mouse was not surprising and could be explained by several factors. First, the cows were late lactation, whereas the mouse samples were collected at peak lactation. Second, and probably more importantly, cows have a much lower metabolic rate than mice. This metabolic scaling effect is known to occur at the level of mitochondrial function and most likely results from differences in mitochondrial proton leakage (Porter and Brand, 1993; West et al., 2002).

In summary, we have improved techniques for the preparation and analysis of mammary gland mitochondrial function by identifying optimal preparation and cryopreservation conditions and by determining the conditions for a 96-well format assay that will facilitate high-throughput analysis of ATP synthesis activity. Future studies based on these protocols will work to understand the regulation of mitochondrial function in the mammary gland during lactation and other key developmental periods.

\section{ACKNOWLEDGMENTS}

The authors thank Daniel Torres (Department of Pediatrics, Baylor College of Medicine, Houston, TX) for help with some of the analysis. Thanks also to Douglas Burrin (Department of Pediatrics, Baylor College of Medicine) for a critical review of the manuscript. This project was supported by funds from the USDA cooperative agreement \#58-6250-6001 (DLH) and CSREES \# 2007-35206-17831 (DLH).

\section{REFERENCES}

Anzai, T., K. Muto, and S. Komine. 1979. Changes in fat content and some characteristics of lipolytic activity during pregnancy and lactation in mouse mammary gland. Endocrinol. Jpn. 26:371377 .

Baumrucker, C. R. 1978 Calcium transport in lactation. Pages 463-473 in Lactation. B. L. Larson, ed. Academic Press, New York, NY.

Benz, R., and S. McLaughlin. 1983. The molecular mechanism of action of the proton ionophore FCCP (carbonylcyanide p-trifluoromethoxyphenylhydrazone). Biophys. J. 41:381-398.

Boime, I., E. E. Smith, and F. E. Hunter Jr. 1970. The role of fatty acids in mitochondrial changes during liver ischemia. Arch. Biochem. Biophys. 139:425-443.

Bradshaw, P. C., and D. R. Pfeiffer. 2006. Release of $\mathrm{Ca}^{2+}$ and $\mathrm{Mg}^{2+}$ from yeast mitochondria is stimulated by increased ionic strength. BMC Biochem. 7:4.

Brustovetsky, N. N., M. V. Egorova, D. Y. Gnutov, V. G. Gogvadze, E. N. Mokhova, and V. P. Skulachev. 1992. Thermoregulatory, carboxyatractylate-sensitive uncoupling in heart and skeletal muscle mitochondria of the ground squirrel correlates with the level of free fatty acids. FEBS Lett. 305:15-17.

Cadenas, S., and M. D. Brand. 2000. Effects of magnesium and nucleotides on the proton conductance of rat skeletal-muscle mitochondria. Biochem. J. 348:209-213.

Cassidy, M. M., A. M. Goldner, and C. S. Tidball. 1969. Subcellular localization of calcium, magnesium, and protein in canine intestinal mucosa. Am. J. Physiol. 217:680-685.

Chen, R. F. 1967. Removal of fatty acids from serum albumin by charcoal treatment. J. Biol. Chem. 242:173-181.

Darley-Usmar, V. M., D. Rickwood, and M. T. Wilson. 1987 Mitochondria: A practical approach. Oxford Press, Washington, DC.

Davis, B. D., and R. J. Dubos. 1948. The inhibitory effect of lipase on bacterial growth in media containing fatty acid esters. J. Bacteriol. 55:11-23.

Dreels, J. M., and C. R. Baumrucker. 1982. Bovine milk-associated calcium as an uncoupling factor of mitochondrial respiration. J. Dairy Sci. 65:1141-1147.

Goodman, D. S. 1958. The interaction of human serum albumin with long-chain fatty acid anions. J. Am. Chem. Soc. 80:3892-3898.

Gunter, T. E., D. I. Yule, K. K. Gunter, R. A. Eliseev, and J. D. Salter. 2004. Calcium and mitochondria. FEBS Lett. 567:96-102.

Kadenbach, B. 2003. Intrinsic and extrinsic uncoupling of oxidative phosphorylation. Biochim. Biophys. Acta 1604:77-94.

Kuhn, N. J. 1967. Regulation of triglyceride synthesis in the parturient guinea-pig mammary gland. Biochem. J. 105:225-231.

Kuznetsov, A. V., W. S. Kunz, V. Saks, Y. Usson, J. P. Mazat, T. Letellier, F. N. Gellerich, and R. Margreiter. 2003. Cryopreservation of mitochondria and mitochondrial function in cardiac and skeletal muscle fibers. Anal. Biochem. 319:296-303.

Lehninger, A. L., C. S. Rossi, E. Carafoli, and B. Reynafarje. 1969 Energy-independent and energy-dependent interactions of cations with mitochondria. Pages 369-377 in Mitochondria, Structure and Function. L. Ernster, and Z. Drahota, ed. Academic Press, London,UK.

Lindberg, G. L., B. B. Shank, M. F. Rothschild, J. E. Mayfield, A. E. Freeman, C. M. Koehler, and D. C. Beitz. 1989. Characteristics of mammary mitochondria in lines of mice genetically divergent for milk production. J. Dairy Sci. 72:1175-1181.

Liu, S. S., and C. T. Chin. 1964. Oxidative phosphorylation and respiratory control in the mitochondria isolated from the flight muscle of the armyworm moth, leucania separata walker. Sci. Sin. 13:689-692.

Lund, P., and D. Wiggins. 1990. Maintenance of energy-linked functions in rat liver mitochondria. Biochim. Biophys. Acta 1018:98-102.

Manfredi, G., L. Yang, C. D. Gajewski, and M. Mattiazzi. 2002. Measurements of ATP in mammalian cells. Methods 26:317326.

Masola, B., and D. F. Evered. 1984. Preparation of rat enterocyte mitochondria. Biochem. J. 218:441-447.

Mehard, C. W. 1974. Isolation of mitochondria from mouse mammary gland. Methods Enzymol. 31:305-310.

Mootha, V. K., P. Lepage, K. Miller, J. Bunkenborg, M. Reich, M. Hjerrild, T. Delmonte, A. Villeneuve, R. Sladek, F. Xu, G. A. Mitchell, C. Morin, M. Mann, T. J. Hudson, B. Robinson, J. D. Rioux, and E. S. Lander. 2003. Identification of a gene causing human cytochrome c oxidase deficiency by integrative genomics. Proc. Natl. Acad. Sci. USA 100:605-610.

Nelson, W. L., R. A. Butow, and E. I. Ciaccio. 1962. Oxidative phosphorylation in guinea pig mammary gland mitochondria during various functional states. Arch. Biochem. Biophys. 96:500-505.

Nicholls, D. G. 2005. Mitochondria and calcium signaling. Cell Calcium 38:311-317.

Pallotti, F., and G. Lenaz. 2001. Isolation and subfractionation of mitochondria from animal cells and tissue culture lines. Methods Cell Biol. 65:1-35.

Porter, R. K., and M. D. Brand. 1993. Body mass dependence of H+ leak in mitochondria and its relevance to metabolic rate. Nature 362:628-630. 
Rodriguez-Zavala, J. S., and R. Moreno-Sanchez. 1998. Modulation of oxidative phosphorylation by $\mathrm{Mg}^{2+}$ in rat heart mitochondria. J. Biol. Chem. 273:7850-7855.

Roussel, D., J. F. Dumas, A. Augeraud, O. Douay, F. Foussard, Y. Malthiery, G. Simard, and P. Ritz. 2003. Dexamethasone treatment specifically increases the basal proton conductance of rat liver mitochondria. FEBS Lett. 541:75-79.

Rubin, R. P. 1974 Calcium and the secretory process. Plenum Press, New York, NY.

Saris, N. E., and E. Carafoli. 2005. A historical review of cellular calcium handling, with emphasis on mitochondria. Biochemistry (Mosc.) 70:187-194.

Schindl, R., J. Weghuber, C. Romanin, and R. J. Schweyen. 2007. Mrs2p forms a high conductance $\mathrm{Mg}^{2+}$ selective channel in mitochondria. Biophys. J. 93:3872-3883.

Schmid, R. W., and C. N. Reilley. 1957. New complexonfor titration of calcium in the presence of magnesium. Anal. Chem. 29:264-267.
Schmitz, C., F. Deason, and A. L. Perraud. 2007. Molecular components of vertebrate $\mathrm{Mg}^{2+}$-homeostasis regulation. Magnes. Res. 20:6-18.

Smith, S., H. T. Gagne, D. R. Pitelka, and S. Abraham. 1969. The effect of dietary fat on lipogenesis in mammary gland and liver from lactating and virgin mice. Biochem. J. 115:807-815.

West, G. B., W. H. Woodruff, and J. H. Brown. 2002. Allometric scaling of metabolic rate from molecules and mitochondria to cells and mammals. Proc. Natl. Acad. Sci. USA 99(Suppl. 1):24732478.

Wojtczak, A. B., E. Lagwinska, and L. Wojtczak. 1968. Oxidative phosphorylation in mitochondria of the wax moth and some other insects. Acta Biochim. Pol. 15:15-29.

Zsurka, G., J. Gregan, and R. J. Schweyen. 2001. The human mitochondrial Mrs2 protein functionally substitutes for its yeast homologue, a candidate magnesium transporter. Genomics $72: 158-168$. 